\section{Reap the benefits of the Nagoya Protocol}

Parties to the Nagoya Protocol on access to genetic resources and fair sharing of the resulting benefits met last month in South Korea to mark the protocol coming into force. Informal hallway discussions showed signs of a welcome new approach to non-commercial research.

An off-shoot of the Convention on Biological Diversity, the Nagoya Protocol provides a framework for countries to draft legislation that governs access and benefit-sharing agreements. Twelve years of negotiations were adversarial and pervaded by concerns over biopiracy - the creation of biological products from native species without consent or compensation for the country of origin (see Nature 514, 14-15; 2014).

During the negotiations, some countries with rich biodiversity imposed restrictive access regulations on commercial and non-commercial researchers to reduce the risk of biopiracy. This caused interest to wane among taxonomists, ecologists and other non-commercial scientists who could help nations to discover, document and manage their biodiversity.

Now, several countries have shown a renewed interest in international collaborations for non-commercial research. They are concluding that two decades of restrictions and intensive monitoring of non-commercial research has revealed no biopiracy, only academic papers.

If this trend continues, permits for specimen-collecting and research could become easier to obtain if researchers agree not to use samples for commercial activities without prior consent. This follows the protocol's recommendation to promote non-commercial research that encourages conservation and sustainable use.

Also, formal arrangements for sharing financial benefits could be delayed until a researcher wants to use genetic resources for commercialization (for instance, patents on active ingredients or industrial application of gene sequences). Most noncommercial research projects never reach this stage.

By facilitating access for non-commercial research, provider countries will reap non-monetary benefits such as training, technology transfer and greater understanding of their biodiversity.

David E. Schindel National Museum of Natural History, Smithsonian Institution, Washington DC, USA. schindeld@si.edu

Pierre du Plessis CRIAA Southern African Development and Consulting, Windhoek, Namibia.

\section{Endangered species damned by dams}

Hydroelectric projects in India's Eastern Himalayas risk damaging this world biodiversity hot spot, which is home to many endangered species. Government agencies should scrupulously assess the environmental impact of such huge projects before approving them.

For example, estimates suggest that there are currently fewer than 300 freshwater South Asian river dolphins (Platanista gangetica gangetica) in the Brahmaputra River and its tributaries. Of the 170 or so dams that are planned or under construction there, some will change the river's morphology and hydrology, degrading or destroying the deep pools that form the dolphins' natural habitat and further endangering these rare mammals (see A. Wakid Curr. Sci. 97, 11431151 (2009); see also M. K. Pandit et al. BioScience http://doi.org/ wqm; 2014).

The dams' cumulative impact on downstream wetland and floodplain ecosystems also threatens Kaziranga National Park in Assam, which hosts the world's highest density of endangered Bengal tigers

(Panthera tigris tigris) and a major population of Indian rhinoceroses (Rhinoceros unicornis).

Likewise, the Kurichu dam on the Manas River and the Mangdechhu dam on the Mangde River in Bhutan pose a threat to the Manas Wildlife Sanctuary in Assam, which was on the World Heritage Committee's danger list as recently as 2011.

Pankaj Barah, Kaveri Bhuyan Norwegian University of Science and Technology, Trondheim, Norway. pankaj.barah@ntnu.no

\section{Navigation Nobel: Soviet pioneer}

Physiologist Ivan Beritashvili was notably absent from the acknowledged forerunners in the scientific background document for this year's Nobel Prize in Physiology or Medicine (see Nature 514, 153; 2014). In the 1930s, he studied spatial navigation in dogs at the University of Tbilisi in Georgia.

John O'Keefe, one of the Nobel winners, had many of Beritashvili's works translated into English. References to Beritashvili have appeared in several books and reviews (see, for instance, P. F. Smith and Y. Zheng Front. Integr. Neurosci. http://doi.org/wrj (2013); I. Bures and O. Buresova in Machinery of the Mind (eds E. R. John et al.) Springer, 1990), and evidence of his pioneering research was presented by neurophysiologist Merab Tsagareli at a September 2014 conference on early Soviet and Russian contributions to the 'science of anticipation' (see go.nature.com/oc4cl8).

In my view, Beritashvili, as the first to study spatial navigation in higher vertebrates, deserves a mention in the Nobel background document. His contributions warrant reappraisal, as do those of many other scientists who worked in the former Soviet Union and who were often vilified and isolated from the international scientific community.
Mihai Nadin Institute for Research in Anticipatory Systems, University of Texas at Dallas, Richardson, Texas, USA. nadin@utdallas.edu

\section{Navigation Nobel: ways to help the lost}

We now understand why people with dementia often wander and get lost, thanks largely to work by the winners of last month's Nobel Prize in Physiology or Medicine (see Nature 514, 153; 2014). But we still need to help the millions of people worldwide who have damaged navigation systems.

Almost $40 \%$ of people with dementia wander (R. McShane et al. Int. Psychogeriatr. 10, 253-260; 1998), and it is a major reason for institutionalization. Fitting people with a tracking device might help (see R. McShane Br. Med. J. 346, f3603; 2013), but this raises ethical challenges (see D. O’Neill Br. Med. J. 346, f3606; 2013). Medication is another quick fix, but merely sedates these vulnerable individuals.

We need to better equip places that have a growing population of disorientated people, including hospitals, longterm care facilities and homes. Strategies such as daily exercise, comforting and distracting coverings for walls and doors, even simply asking individuals what they need, can all help.

Such low-cost, high-touch tactics do not involve pills, side effects or major profit for anyone. Let's start implementing these measures, without getting lost along the way.

Raza M. Naqvi London Health Sciences Centre, Ontario, Canada. raza.naqvi@lhsc.on.ca

\section{CONTRIBUTIONS}

Correspondence may be sent to correspondence@ nature.com after consulting the guidelines at http:// go.nature.com/cmchno. 